\title{
Effects of Fermented Sea Tangle Supplementation on the Oxidative Stress and DNA Damage in Older Women
}

\author{
Byeong Hwan Jeon ${ }^{1 *}$
}

${ }^{1}$ Kyungsung University

Received: November 21, 2018
Accepted: March 25, 2019
Published online: April 30, 2019
Keywords:
8-Hydroxydeoxyguanosine
(8-OHdG)
Aging
Oxidative Stress
Sea Tangle

Check for
updates

\section{ABSTRACT}

OBJECTIVES The free radical theory of aging posits that a decrease in antioxidant capacity occurs in old age. This exposes the body to greater oxidative stress, which has been reported to have a causal effect on the aging process and development of disease. Sea tangle is a fermented food source shown to provide a reducing antioxidant effect.

METHODS Forty senior women participated in a randomized, double-blind, and placebo-controlled study. Two groups were formed, one placebo $(74.57 \pm 5.69 \mathrm{yrs}$ ) and one FST (fermented sea tangle) group (72.35 $\pm 5.54 \mathrm{yrs}$ ), which received $1.5 \mathrm{~g} /$ day of FST for 6 weeks.

RESULTS Serum superoxide dismutase (SOD), glutathione peroxidase (GPX), glutathione reductase (GSR), thiobarbituric reactive species (TBARS) and 8-hydroxodeoxyguanosine (8-OHdG) levels were analyzed before and after the experimental period. FST supplementation significantly increased serum SOD and GSR levels. Whereas, levels of oxidative stress markers, TBARS and 8-OHdG were significantly decreased in comparison to those in the placebo group, after 6 weeks.

CONCLUSIONS Our results suggest that FST can act as an effective exogenous antioxidant intervention against the dwindling efficiency of our biological defenses and/or increased intracellular reactive oxygen and DNA damage levels, associated with aging.

() The Asian Society of Kinesiology and the Korean Academy of Kinesiology

\section{Introduction}

The prevention of age-related degeneration and diseases such as, cancer, diabetes, liver disease, stroke and neurodegeneration, continue to dominate medical research $[1,2]$. Oxidative stress has been implicated as a key contributing factor in the development of these conditions [3,4]. It has been shown that high levels of reactive oxygen species (ROS) causes damage to cellular proteins, membrane lipids and nucleic acids, leading eventually to cell death and the onset of disease

*Correspondence: Byeong Hwan Jeon, Sports and health science, Kyungsung University, 309 Suyung-ro, Busan, Republic of Korea; Tel: +82-51-663-4951; Fax : +8251-663-4959; E-mail: mooaworld@ks.ac.kr
[5]. Thus, in order for our bodies to effectively respond to oxidative stress and restore a "normal" cellular redox balance, an up-regulation of these low-molecular-weight antioxidants and protective enzymes must occur [6].

Studies investigating the use of edible seaweeds to regulate biological systems have grown in number. Of these, Sea tangle (Laminaria japonica), an age-old Pacific and Asian food resource - typically consumed for its high contents of dietary fiber, carbohydrates, minerals and protein - has attracted growing interest for its bioactive potency and prophylactic activity $[7,8]$. Previous studies have supported the benefits of sea tangles for degenerative chronic diseases through 
antioxidant effects $[9,10]$, as well as its hypotensive effects [11], anti-hyperlipidemic and anti-atherosclerotic activities [12].

In order to increase the GABA (gamma amino butyric acid) contents within sea tangle and elicit significant antioxidant effects, recent studies have implemented a specified fermentation process using Lactobacillus brevis BJ20. The results of these studies have indicated that superoxide radical scavenging, catalase (CAT) and glutathione peroxidase (GPx) activity were enhanced, whereas the lipid peroxidation level was diminished following fermented sea tangle (FST) supplementation $[13,14]$.

It is well documented that another, particularly damaging, effect of ROS and RNS is on DNA structure and function; typically resulting in base modification [15], single and double-strand breaks [16], damage to the DNA repair system [17], and associated with carcinogenesis [4]. Most damage is caused by the hydroxyl radical (OH.), which is considered the most powerful oxidizing agent in biological systems due to its very high reactivity and short half-life [18]. The presence of other reactive species, such as superoxide $\left(\mathrm{O}_{2}^{-}\right)$and hydrogen peroxide $\left(\mathrm{H}_{2} \mathrm{O}_{2}\right)$ also provide a source for other reactive intermediates that can collectively result in the production of hydroxyl radicals. To our knowledge, only one previous study has evaluated the antioxidant effects of FST within a clinical trial setting [13], and no studies have yet reported its possible protective provision for DNA. This coupled with the growing evidence that antioxidant capacity decreases with age [19], forms the premise of the current study, which aims to investigate the effects of FST supplementation on antioxidant capacity in aged women.

\section{Methods}

\section{Subjects}

Forty, moderately active, senior women (72.8 \pm 5.0yrs) participated in a randomized, double-blind and placebocontrolled study (Table 1). Two groups were formed, one placebo group $(73.6 \pm 4.6$ yrs $)$ and one FST group $(72.0 \pm$ 5.5yrs). Subjects suffering with hypertension, diabetes, chronic degenerative disease (arthritis), cardiovascular disease, and/or obesity were excluded from the study. Participants were also excluded if they experienced adverse reaction to supplementation prior to the experimental period or were unable to participate due to particular medication. All participants completed a written informed consent to partake in this study, which was approved by Kyungsung University Ethics Committee (KSU-16-05-001).

\section{Material preparation and treatment}

FST was prepared following a recently modified procedure [20]. Sea tangle was added to water at a ratio of 1:15 (w/v) with the addition of yeast extract and glucose, based on the amount of sea tangle added to the mixture. After autoclaving at $121^{\circ} \mathrm{C}$ for $30 \mathrm{~min}$, a sea tangle solution was obtained and the culture broth (Lactobacillus brevis BJ20) was added to the solution at a concentration of $1.2 \%(\mathrm{v} / \mathrm{v})$ (Table 2$)$, which was mixed and incubated at $37^{\circ} \mathrm{C}$ for 2 days (Figure 1).

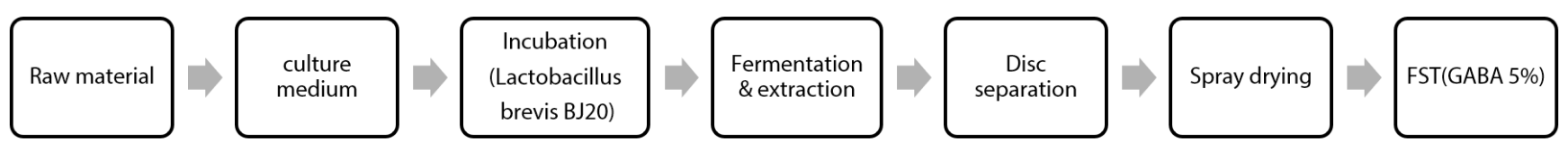

Figure 1 . Preparation process of FST from raw sea tangle

\begin{tabular}{|c|c|c|c|c|c|c|c|c|c|}
\hline \multirow{2}{*}{ group } & \multirow{2}{*}{ value } & \multirow{2}{*}{ Age (year) } & \multirow{2}{*}{$\begin{array}{c}\text { Height } \\
\text { (cm) }\end{array}$} & \multicolumn{2}{|c|}{ Weight (kg) } & \multicolumn{2}{|c|}{ SBP $(\mathbf{m m H g})$} & \multicolumn{2}{|c|}{$\mathrm{DBP}(\mathrm{mmHg})$} \\
\hline & & & & pre & post & pre & post & pre & post \\
\hline \multirow[t]{2}{*}{ FST } & mean & 72.0 & 158.3 & 59.3 & 59.2 & 126.7 & 125.4 & 77.3 & 76.4 \\
\hline & SD & 5.5 & 5.7 & 6.9 & 6.8 & 17.6 & 32.9 & 8.6 & 8.4 \\
\hline \multirow[t]{2}{*}{ Placebo } & mean & 73.6 & 153.9 & 54.4 & 53.7 & 134.4 & 134.7 & 78.1 & 82.4 \\
\hline & SD & 4.6 & 5.0 & 5.3 & 6.7 & 11.8 & 19.7 & 9.2 & 11.9 \\
\hline
\end{tabular}


Based on a previous clinical study [20], the content of GABA within FST was controlled to range between 40 60 mg within 1,000 $\mathrm{mg}$ of FST using high performance liquid chromatography analysis during the preparation process. Participants ingested either 1,000 mg of FST (FST) per day or 1,000 mg sucrose placebo (CON) per day, for 6 weeks. Subjects were asked to abstain from any regular exercise. Fasting venous blood samples were taken before (pre-experiment) and after (post-experiment) the 6 weeks' period. Collected blood samples were clotted for $30 \mathrm{~min}$ and centrifuged for $15 \mathrm{~min}$ at $1,000 \times \mathrm{g}$ to separate into serum, and stored at $-80^{\circ} \mathrm{C}$ and analyzed by immunoassay.

\begin{tabular}{|c|c|c|c|c|c|c|}
\hline & $\begin{array}{c}\text { Sea } \\
\text { tangle }\end{array}$ & Water & $\begin{array}{c}\text { Yeast } \\
\text { extract }\end{array}$ & Glucose & $\begin{array}{l}\text { Seed } \\
\text { culture }\end{array}$ & Total \\
\hline Weight (g) & 408.5 & $6,127.5$ & 10 & 5 & 76.5 & $6,627.5$ \\
\hline $\begin{array}{l}\text { Percentage } \\
\text { (\%) }\end{array}$ & 6.2 & 92.5 & 0.2 & 0.1 & 1.2 & 100 \\
\hline
\end{tabular}

\section{Measurements}

Serum SOD (Superoxide dismutase) level was determined using a commercially available kit, Cayman's Superoxide dismutase assay kit (Cayman Chemical Company, Ann Arbor, MI, USA). Tetrazolium salt was utilized to detect superoxide radicals generated by xanthine oxidase and hypoxanthine, which react to form a yellow formazan dye. The detection limit of the assay was $0.025-0.25 \mathrm{U} / \mathrm{ml}$ SOD. Inter and intraassay coefficients of variation were 3.7 and $3.2 \%$, respectively. Absorbance was measured at a wavelength of 440-460 nm and enzyme activity $(\mathrm{U} / \mathrm{ml})$ was calculated.

Serum GPx (Glutathione peroxidase) level was measured using the Cayman GPx Assay Kit (Cayman Chemical Company, Ann Arbor, MI, USA). The Co-substrate mixture contained NADPH, glutathione, and glutathione reductase, and the reaction was initiated by adding $20 \mu \mathrm{l}$ of cumene hydroperoxide. One unit of GPx was defined as the amount of enzyme that catalyzes the oxidation of $1.0 \mathrm{nmol}$ of $\mathrm{NADPH}$ per minute at $25^{\circ} \mathrm{C}$. Absorbance was measured at a wavelength of $340 \mathrm{~nm}$ and enzyme activity $(\mathrm{U} / \mathrm{ml})$ was calculated.

Serum GSR (Glutathione reductase) level was measured using the commercially available Cayman Chemical
Glutathione Reductase Assay Kit (Cayman Chemical Company, Ann Arbor, MI, USA), which measures the rate of NADPH oxidation. The reaction was initiated by adding $50 \mu \mathrm{l}$ of NADPH and this is accompanied by a rapid decrease in the absorbance at $340 \mathrm{~nm}$. One unit of GSR activity was calculated as the amount of enzyme that catalyzes the oxidation of 1.0 nmol of NADPH per minute at $25^{\circ} \mathrm{C}$

Serum TBARS (thiobarbituric reactive species) content was determined with the OxiSelect ${ }^{\mathrm{TM}}$ TBARS Assay Kit, a commercial kit provided by Cell Biolabs Inc. (San Diego, CA, USA). The malondialdehyde containing samples were first reacted with $\mathrm{TBA}$ at $95^{\circ} \mathrm{C}$. After a brief incubation, the malondialdehyde protein adducts content in the serum was determined by comparison with a predetermined malondialdehyde standard curve. Spectophotometric measurement was used to calculate serum TBARS content $(\mu \mathrm{M})$ at $532 \mathrm{~nm}$ absorbance.

Oxidative stress marker to DNA, 8-OHdG (8-hydroxodeoxyguanosine) was measured using a competitive enzyme-linked immunosorbent assay kit from JaICA (Japan Institute for the Control of Aging, Shizuoka, Japan), following manufacturers' instructions. This test used a monoclonal antibody N45.1. Absorbance from the wells was measured at $450 \mathrm{~nm}$ with a microtiter plate reader.

\section{Statistical Analysis}

All statistical analyses were conducted with SPSS Windows version. 21.0. In order to verify the impact of FST supplementation, two-way analysis of variance (ANOVA) with repeated measure was conducted to assess the main effects between groups. Descriptive statistics were used to report on each variable. Statistical significance was set at $\alpha=0.05$.

\section{Results}

Prior to the experimental period the baseline values of serum SOD in the FST and placebo group were $5.56 \pm 0.35$ $\mathrm{U} / \mathrm{ml}$ and $5.70 \pm 0.47 \mathrm{U} / \mathrm{ml}$, respectively. As shown in Figure $2 \mathrm{~A}$, SOD levels in the FST group $(6.15 \pm 0.46 \mathrm{U} / \mathrm{ml})$ tended to increase, whereas the placebo group $(5.29 \pm 0.55 \mathrm{U} / \mathrm{ml})$ tended to decrease. But there was no significant difference in main effect between groups (FST treatment) $(\mathrm{p}=.353)$ or within 
groups (time, 6-week period) $(\mathrm{p}=743)$ in serum SOD levels. However, there was a significant interaction effect between FST treatment and time in serum SOD $(\mathrm{p}<.01)$.

Following treatment, GPx levels in the FST group increased $(195.57 \pm 43.96 \mathrm{nmol} / \mathrm{min} / \mathrm{ml}$ to $217.73 \pm 56.95$ $\mathrm{nmol} / \mathrm{min} / \mathrm{ml}$ ), whereas the placebo group tended to decrease $(190.89 \pm 43.02 \mathrm{nmol} / \mathrm{min} / \mathrm{ml}$ to $182.29 \pm 38.94 \mathrm{nmol} / \mathrm{min} /$

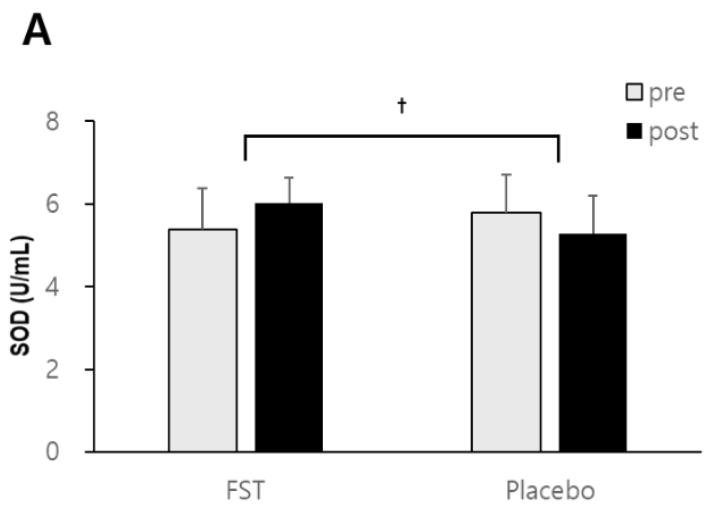

B
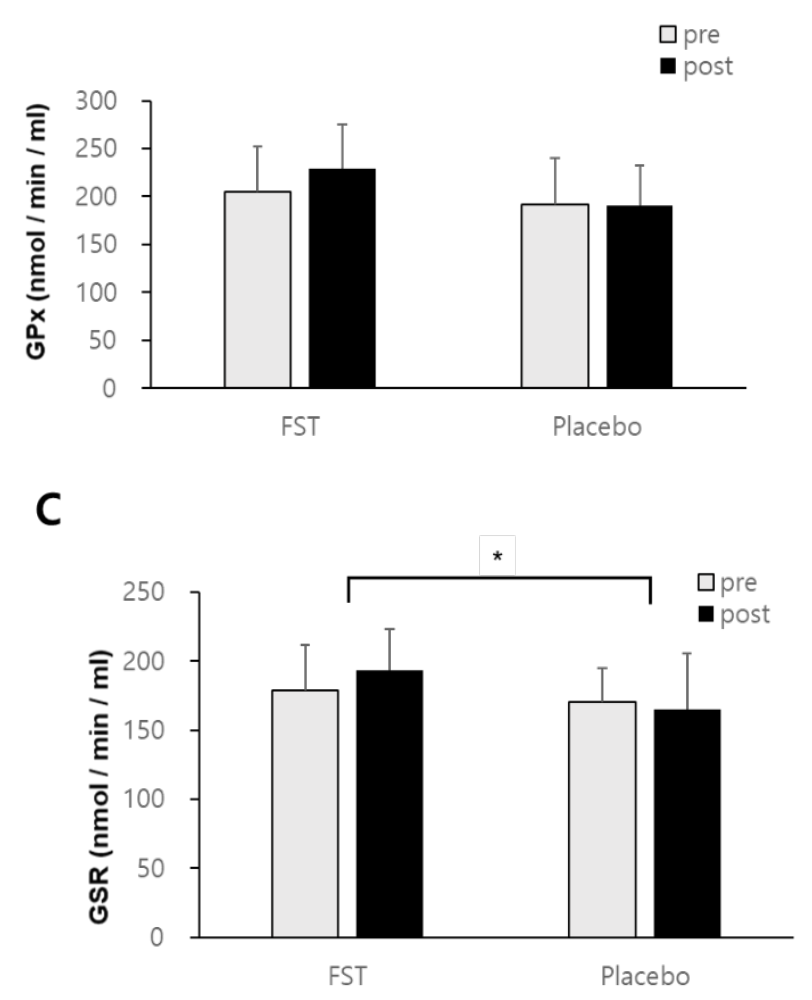

Figure 2. Serum (A) SOD, (B) GPx, (C) GSR levels analyzed using a two-way repeated measures ANOVA in the FST and placebo group, pre-and postexperimental trial. Each bar represents the mean \pm SD.

$\left(\mathrm{tp}<.05\right.$ : the interaction effect of FST treatment and time between groups, ${ }^{*} \mathrm{p}$ $<.05$ : the main effect of FST treatment between groups) ml) (Figure 2B). Statistically, GPx level in the FST group was not significantly different compared to that of the placebo group following the 6-week supplementation period $(\mathrm{p}=.055)$. However, there is no significance within groups (time, 6-week period $)(\mathrm{p}=.051)$

GSR levels in serum tended toward an increase in the FST group $(179.73 \pm 22.73 \mathrm{nmol} / \mathrm{min} / \mathrm{ml}$ to $195.751 \pm 18.63 \mathrm{nmol} /$ $\mathrm{min} / \mathrm{ml}$ ), while conversely, a slight decrease was recorded in the placebo group $(171.79 \pm 25.19 \mathrm{nmol} / \mathrm{min} / \mathrm{ml}$ to $158.14 \pm$ $35.55 \mathrm{nmol} / \mathrm{min} / \mathrm{ml}$ ) (Figure 2C). Statistically, the main effect of FST supplementation on serum GSR levels was significant such that the FST group had higher levels than the placebo group following the 6 -week treatment $(\mathrm{p}<.01)$. However, there is no significance within groups (time, 6-week period) $(\mathrm{p}=.450)$.

The results of this study showed a reduction in TBARS values in both the FST group $(6.58 \pm 0.84 \mu \mathrm{M}$ to $5.67 \pm 0.65$ $\mu \mathrm{M})$ and placebo group $(6.89 \pm 0.72 \mu \mathrm{M}$ to $6.71 \pm 1.35 \mu \mathrm{M})$ (Figure 3). The between groups difference following 6 weeks of FST supplementation $(\mathrm{p}<.05)$ and within groups before and after the treatment $(\mathrm{p}<.05)$ were significant. Whereas, there was no significant interaction effect between FST treatment and time in serum TBARS level $(\mathrm{p}=.273)$.

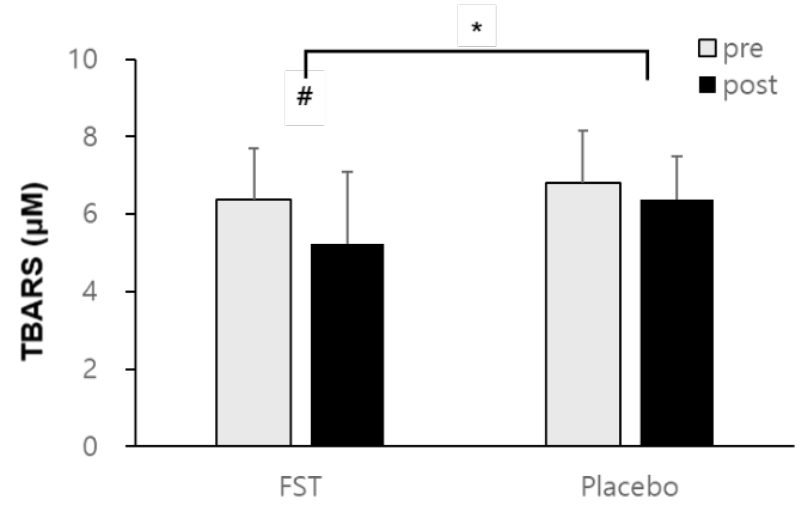

Figure 3. Serum TBARS levels analyzed using a two-way repeated measures ANOVA in the FST and placebo group, pre-and post-experimental trial. Each bar represents the mean \pm SD.

( ${ }^{*} p<.05$ : the main effect of FST treatment between groups, $\# p<.05$ : the main effect of time within group).

In regard to oxidative damage to DNA, 8-OHdG levels were significantly decreased within FST $(2.39 \pm 0.44 \mathrm{ng} /$ $\mathrm{ml}$ to $6.89 \pm 0.72 \mathrm{ng} / \mathrm{ml}$ ) whereas placebo groups were not statistically changed $(2.57 \pm 0.40 \mathrm{ng} / \mathrm{ml}$ to $2.46 \pm 0.56 \mathrm{ng} / \mathrm{ml})$ 
(Figure 4). These resulted in a significant difference in both between groups (FST supplementation) $(\mathrm{p}<.01)$ and within group (time) $(\mathrm{p}<.01)$ after the 6-week treatment. A significant interactive effect of FST treatment and time $(\mathrm{p}<.05)$ was also demonstrated in serum 8-OHdG levels.

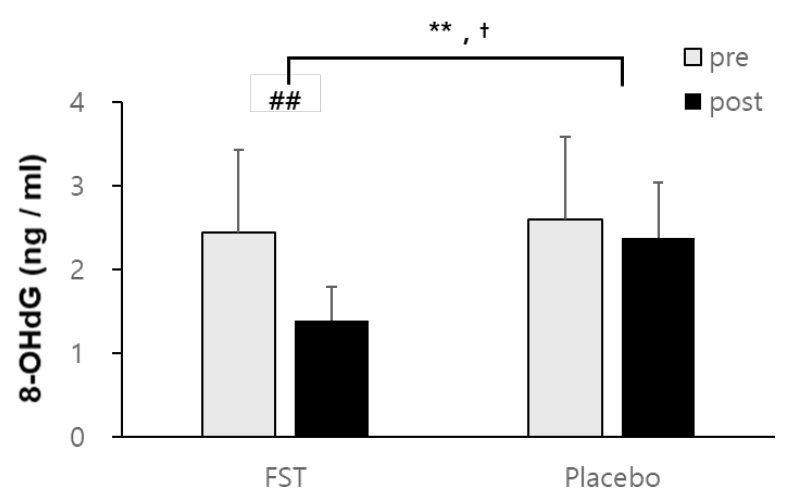

Figure 4. Serum 8-OHdG (8-hydroxodeoxyguanosine levels analyzed using a two-way repeated measures ANOVA in the FST and placebo group, pre-and post-experimental trial. Each bar represents the mean \pm SD.

$(t p<.05$ : the interactive effect of FST treatment and time between groups, ${ }^{* *} \mathrm{p}<.01$ : the main effect of FST treatment between groups, \#\#p <.01: the main effect of time within group)

\section{Discussion}

Sea tangle, L. japonica, has been investigated for its numerous health preserving and enhancing effects [9-12], including its antioxidant properties [13-14]. The current study demonstrated that FST supplementation for a 6-week period enhanced the serum level of SOD and GSR (Figure 2 ), while reducing biomarkers of lipid peroxidation (TBARS) and oxidative DNA damage (8-OHdG) (Figure 3, 4). These results have shed greater light on the antioxidant potential of FST, supporting initial investigations suggesting a protective effect against lipid peroxidation [12] and an enhancement in the enzymatic antioxidant defense system [7, 13], thereby combating the cytotoxic oxidants that mediate the pathogenesis of many chronic diseases.

The cells' main defense mechanism against oxygen free radicals includes enzymes such as SOD, GSR and GPx, among other low molecular weight antioxidants and antioxidant nutrients. Lee et al. [13] reported that FST quenched $\mathrm{O}^{2-}$ radicals; while Kang et al. [14] went on to demonstrate a significant augmentation in SOD activity following 4 weeks of FST supplementation. It is of particular importance that the present study corroborated these results in senior subjects, whose aging cells grow increasingly inefficient at eliminating oxidative stressors seen particularly in the mitochondrion, where there is increased ROS production and even damaged membrane integrity with age [21]. The scavenging of $\mathrm{O}_{2}^{-}$by SOD will reduce $\mathrm{OH}$ production and potential site-specific biological damage to lipid membranes, proteins and DNA [22].

Though there is a reactive byproduct of SOD in the form of $\mathrm{H}_{2} \mathrm{O}_{2}$, it may be effectively detoxified to water by GPx in a reduction reaction involving glutathione (GSH) [23]. Reduced GPx activity has been identified as a predictor of increased cardiovascular risk $[24,25]$. Six weeks of FST administration in this study, however, did not lead to the significant enhancement of GPx level (Figure 2B). These results are supported by a previous study [15] in which FST ingestion for 4 weeks showed no significant effect on GPx activity. However, a longer experimental period may have rendered differing by FST supplementation [20]. Taken together, a longer treatment period, potentially 8 weeks, may be required to demonstrate an enhancement of serum GPx levels in the older women.

Tight regulation of GSH, and its oxidized form (GSSG), is imperative to cell survival; so much so that an imbalance in GSH has been linked to a wide range of pathologies, including Alzheimer's disease, aging [26], and cancer [27]. GSR works hand-in-hand with GPx to help regulate the redox state of GSH (GSH : GSSG ratio), including decomposition of $\mathrm{H}_{2} \mathrm{O}_{2}$. Thus, reducing levels of GSR reported in the latter stages of life [28], particularly concerning to the aging population. Our study demonstrated a significant difference in GSR activity between the FST and CON groups (Figure 2C). GSH is a vital scavenger, recycled by GSR to combat oxidative stress, therefore an up-regulation of GSR via dietary intervention would aid in optimizing its redox state, and thus reduce deleterious oxidative damage.

Cellular membranes are especially susceptible to oxidation due to their high concentrations of polyunsaturated fatty acids [29]. In consistent with previous findings [7, 15, 16], we showed that fermented L. japonica intake had a significant ameliorative effect on lipid peroxidation, lowering TBARS (Figure 3). TBARS, thiobarbituric reactive species is the 
end product of whole-organism lipid peroxidation [30]. If the deleterious modification of cellular membranes can be alleviated by dietary supplementation, FST may provide a viable defense against lipid-peroxidation-associated conditions such as arteriosclerosis, neurodegenerative disease, and cardiovascular disease [31].

Research has not been undertaken concerning the antioxidant effects of FST supplementation on oxidative damage to DNA, to our knowledge. Thus, the present study recorded the changes in the DNA-oxidized adduct, 8-OHdg following FST supplementation. A significant protective effect against free radical-induced DNA damage was observed in the FST group, compared to the CON (Figure 4). This finding is important, as 8-OHdg is one of the predominant forms of free radical-induced oxidative lesion and widely considered a critical biomarker of oxidative stress and carcinogenesis [32]. Increased 8-OHdg has also been implicated in both nuclear and mitochondrial DNA damage, associated with age [33]. Therefore, FST may be considered an effective and versatile dietary source of antioxidants, capable of providing DNA protection, particularly antimutagenic effects.

\section{Conclusions}

The present study highlighted the widespread antioxidant effects of FST in an elderly population. The upregulation of antioxidant enzyme activity (SOD and GSR) and inhibition of lipid- and DNA-oxidative damage, suggests that FST may be an effective nutritional countermeasure against the age-related increase in oxidative stress.

Considering that some antioxidants, in excessive levels, may be potentially hazardous (e.g., toxicity in humans and DNA oxidation in leukocytes) [34], further research is needed concerning the impact of FST and other dietary interventions on the antioxidant defense systems in specific biological sites in the aging population.

\section{Acknowledgments}

This research was supported by Kyungsung University Research Grants in 2017.

\section{Conflicts of Interest}

The author declares no conflict of interest.

\section{References}

1. Tosato M, Zamboni V, Ferrini A, Cesari M. The aging process and potential interventions to extend life expectancy. Clin Interv Aging. 2007; 2:401-412,

2. Sundar Dhilip Kumar S, Houreld NN, Abrahamse H. Therapeutic Potential and Recent Advances of Curcumin in the Treatment of Aging-Associated Diseases. Molecules. 2018; 23(4):E835.

3. Maritim AC, Sanders A, Watkins 3J. Diabetes, oxidative stress, and antioxidants: a review. J Biochem Mol Toxicol. 2003; 17(1):24-38.

4. Reuter S, Gupta SC, Chaturvedi MM, Aggarwal BB. Oxidative stress, inflammation, and cancer: how are they linked? Free Radic Biol Med. 2010; 49(11):16031616.

5. Schieber M, Chandel NS. ROS function in redox signaling and oxidative stress. Curr Biol. 2014; 24(10):R453-62.

6. Espinosa-Diez C, Miguel V, Mennerich D, Kietzmann T, Sánchez-Pérez P, Cadenas S, Lamas S. Antioxidant responses and cellular adjustments to oxidative stress. Redox Biol. 2015; 6:183-97.

7. Lee BJ, Senevirathne M, Kim JS, et al. Protective effect of fermented sea tangle against ethanol and carbon tetrachloride-induced hepatic damage in SpragueDawley rats. Food Chem Toxicol. 2010; 48(4):11231128.

8. Kang YM, Qian ZJ, Lee BJ, Kim YM. Protective effect of GABA-enriched fermented sea tangle against ethanolinduced cytotoxicity in HepG2 cells. Biotechnol Bioprocess Eng. 2011; 16(5):966-970.

9. Han J, Kang S, Choue R, Kim H, Leem K, Chung S, Kim C. Chung, J. Free radical scavenging effect of Diospyros kaki, Laminaria japonica and Undaria pinnatifida. Fitoterapia. 2002; 73:710-712.

10. Wang J, Zhang, Q, Zhang Z, Li Z. Antioxidant activity of sulfated polysaccharide fractions extracted from 
Laminaria japonica. Int J Biol Macromol. 2008; 42(2):127-132.

11. Chiu KW, Fung AYL. The cardiovascular effects of green beans (Phaseolus aureus), common rue (Ruta graveolens), and kelp (Laminaria japonica) in rats. Gen Pharmacol. 1997; 29(5):859-862.

12. Lee SJ, Kim CW, Jang HJ, Cho SY, Choi JW. Antihyperlipidemia and anti-arteriosclerosis effects of Laminaria japonica in Sprague-Dawley rats. Fish Aquat Sci. 2011; 14(4):235-241.

13. Lee BJ, Kim JS, Kang YM et al. Antioxidant activity and $\gamma$-aminobutyric acid (GABA) content in sea tangle fermented by Lactobacillus brevis BJ20 isolated from traditional fermented foods. Food Chem. 2010; 122(1):271-276.

14. Kang YM, Lee BJ, Kim JI, et al. Antioxidant effects of fermented sea tangle (Laminaria japonica) by Lactobacillus brevis BJ20 in individuals with high level of $\gamma$-GT: a randomized, double-blind, and placebocontrolled clinical study. Food Chem Toxicol. 2012; 50(3):1166-1169.

15. Bruner SD, Norman DP, Verdine GL. Structural basis for recognition and repair of the endogenous mutagen 8-oxoguanine in DNA. Nature. 2000; 403(6772):859866.

16. Driessens N, Versteyhe S, Ghaddhab C, et al. Hydrogen peroxide induces DNA single-and double-strand breaks in thyroid cells and is therefore a potential mutagen for this organ. Endocr Relat Cancer. 2009; 16(3):845-856.

17. Dizdaroglu M, Jaruga P, Birincioglu M, Rodriguez H. Free radical-induced damage to DNA: mechanisms and measurement 1, 2. Free Radic Biol Med. 2002; 32(11):1102-1115.

18. Kohen R, Nyska A. Invited review: Oxidation of biological systems: oxidative stress phenomena, antioxidants, redox reactions, and methods for their quantification. Toxicol Pathol. 2002; 30(6):620-650.

19. Harman, D. Aging: a theory based on free radical and radiation chemistry. J Gerontol. 1956; 11(3):298-300.

20. Choi WC, Reid SN, Ryu JK, Kim Y, Jo YH, Jeon BH. Effects of $\gamma$-aminobutyric acid-enriched fermented sea tangle
(Laminaria japonica) on brain derived neurotrophic factor-related muscle growth and lipolysis in middle aged women. Algae. 2016; 31(2):175-187.

21. Brunk UT, Terman A. The mitochondrial-lysosomal axis theory of aging: accumulation of damaged mitochondria as a result of imperfect autophagocytosis.. Eur J Biochem. 2002; 269(8):1996-2002.

22. Kawanishi S, Hiraku Y, Murata M, Oikawa S. The role of metals in site-specific DNA damage with reference to carcinogenesis. Free Radic Biol Med. 2002; 32(9):822832.

23. Chance B, Sies H, Boveris A. Hydroperoxide metabolism in mammalian organs. Physiol Rev. 1979; 59(3):527-605.

24. Buijsse B, Lee DH, Steffen L et al. Low serum glutathione peroxidase activity is associated with increased cardiovascular mortality in individuals with low HDLc's. PloS one. 2012; 7(6):e38901.

25. Holley AS, Harding SA, Sasse A, Miller JH, Larsen PD. Reduced glutathione peroxidase activity predicts increased cardiovascular risk following an acute coronary syndrome. International Cardiovascular Forum Journal. 2016; 6:61-65.

26. Liu H, Wang H, Shenvi S, Hagen TM, Liu RM. Glutathione metabolism during aging and in Alzheimer disease. Ann N Y Acad Sci. 2004; 1019(1):346-349.

27. Townsend DM, Tew KD, Tapiero H. The importance of glutathione in human disease. Biomed Pharmacother. 2003; 57(3):145-155.

28. Sohal RS, Arnold L, Orr WC. Effect of age on superoxide dismutase, catalase, glutathione reductase, inorganic peroxides, TBA-reactive material, GSH/GSSG, $\mathrm{NADPH} / \mathrm{NADP}+$ and NADH/NAD+ in Drosophila melanogaster. Mech Ageing Dev. 1990; 56(3):223-235.

29. Halliwell B, Gutteridge JM. Free radicals in biology and medicine. USA. Oxford University Press. 2015.

30. Junqueira VB, Barros SB, Chan SS, Rodrigues L, Giavarotti L, Abud RL, Deucher GP. Aging and oxidative stress. Mol Aspects Med. 2004; 25(1-2):5-16.

31. Shichiri M. The role of lipid peroxidation in neurological disorders. J Clin Biochem Nutr. 2014; 54(3):151-160.

32. Valavanidis A, Vlachogianni T, Fiotakis C. 8-hydroxy- 
2'-deoxyguanosine (8-OHdG): a critical biomarker of oxidative stress and carcinogenesis. J Environ Sci Health

C Environ Carcinog Ecotoxicol Rev. 2009; 27(2):120139.

33. Hamilton ML, Van Remmen H, Drake JA, et al. Does oxidative damage to DNA increase with age? Proc Natl Acad Sci USA. 2001; 98(18):10469-10474.

34. Fang YZ, Yang S, Wu G. Free radicals, antioxidants, and nutrition. Nutrition. 2002; 18(10):872-879. 